\title{
DESENVOLVIMENTO FONÉTICO-FONOLÓGICO BI/ MULTILÍNGUE E ATENÇÃO - QUESTÕES TEÓRICAS ABORDADAS NO SPEECH LEARNING MODEL (SLM/ SLM-R) E DESAFIOS FUTUROS PARA A PESQUISA EM SEGUNDA LÍNGUA (L2)
}

\author{
Bi/Multilingual Phonetic-Phonological Development And Attention- \\ Theorical Issues Addressed In The Speech Learning Model (SLM/SLM-r) \\ And Future Challengues For Second Language (L2) Research
}

\author{
Bruna da Rosa DE LOS SANTOS \\ Programa de Pós-Graduação em Letras \\ Universidade Federal do Rio Grande do Sul \\ brunadarosa1@hotmail.com \\ https://orcid.org/0000-0003-2605-0543 \\ Ubiratã Kickhöfel ALVES \\ Programa de Pós-Graduação em Letras \\ Universidade Federal do Rio Grande do Sul \\ ukalves@gmail.com \\ https://orcid.org/0000-0001-6694-8476
}

\begin{abstract}
RESUMO: Neste artigo, propomos uma discussão teórica sobre as possíveis implicações atencionais no desenvolvimento fonético-fonológico bi/multilíngue. Para isso, partimos dos apontamentos feitos no Speech Learning Model, ao longo dos anos (FLEGE, 1995, 2003; FLEGE; BOHN, 2021), em relação ao componente cognitivo atencional. Discutiremos as seguintes questões latentes sobre atenção, não aprofundadas no SLM/SLM-r: (i) a possível relação direta entre proficiência e refinamento de categorias fonético-fonológicas; (ii) a conjugação entre percepção-produção, a qual perpassa, inevitavelmente, um contínuo de processamento entre armazenamento e recuperação de informações psico-acústicas; e (iii) o impacto metodológico de se considerar o construto 'atenção', associado ao SLM/SLM-r, nas coletas de dados de produção bi/multilíngue. Tais lacunas psico-cognitivas dentro do modelo e, de forma geral, dentro da área de pesquisa, constituem desafios teóricos e metodológicos nos estudos de desenvolvimento bi/multilíngue, ainda mais numa perspectiva psicolinguística. Dessa forma, abrir o perímetro investigativo para questões mais amplas que envolvem a cognição bi/multilíngue pode contribuir, teórica e me-
\end{abstract}

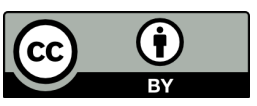


todologicamente, para um maior entendimento do complexo processo de ensino-aprendizagem do componente fonético-fonológico de L2. PALAVRAS-CHAVE: Desenvolvimento fonético-fonológico; SLM/ SLM-r; bi/multilinguismo; atenção.

\begin{abstract}
In this article, we propose a theoretical discussion on the possible attentional implications in bi/multilingual phoneticphonological development. For this, we start from the comments on the attentional cognitive component which were made in the Speech Learning Model over the years (FLEGE, 1995, 2003; FLEGE; BOHN, 2021). We will discuss the following latent issues about attention, which have not been fully addressed in the SLM/SLM-r: (i) the possible direct relationship between proficiency and the refinement of phoneticphonological categories; (ii) the perception-production link, which inevitably permeates a continuum of processing between storage and retrieval of psycho-acoustic information; and (iii) the methodological impact of considering the attentional construct associated with the SLM/ SLM-r in bilingual speech production. Such psycho-cognitive gaps within the model and, in general, within the research area, constitute theoreticalandmethodologicalchallengesinbi/multilingualdevelopment studies, even more so from a psycholinguistic perspective. Thus, opening discussions aiming to broader issues involving bi/multilingual cognition can theoretically and methodologically contribute to a greater understanding of the complex L2 speech teaching-learning process. KEYWORDS: Phonetic-phonological development; SLM/SLM-r; bi/ multilingualism; attention.
\end{abstract}

\title{
INTRODUÇÃO
}

Até o presente momento, uma boa parte da pesquisa brasileira em desenvolvimento fonético-fonológico de Segunda Língua (L2) ${ }^{1}$ se dedicou ao papel exercido pela instrução e pelos tipos de feedback corretivo, implícito e explícito, aplicados em sala de aula (ALVES, 2004; ALVES, 2020; ALVES; LUCHINI, 2020; ALVES; MAGRO, 2011; LIMA JR.; ALVES, 2019; PEROZZO, 2013; RODRIGUES, 2018; SILVEIRA, 2004; entre outros). Também, recentemente, estudos têm debatido o efeito de treinamento

\footnotetext{
${ }^{1}$ Usamos o termo 'fonético-fonológico' porque entendemos que os sons que compõem o repertório linguístico de um falante não são categorias estanques e desvinculadas de suas características psico-acústicas. Portanto, não consideramos a dicotomia entre as tradicionais áreas de Fonética e Fonologia ao tratar do desenvolvimento linguístico. Além disso, consideramos que percepção e produção são processos interconectados que retroalimentam e mudam, constantemente, as categorias de sons armazenadas.
}

Revista X, v. 16, n. 5, p. 1203-1230, 2021. 
perceptual (ALVES; KAMPFF, 2019; ALVES, 2020; ALVES, 2021; BRAWERMANALBINI, 2012; MILAN, 2019) ${ }^{2}$. Nesse contexto investigativo, percebe-se a necessidade de construir uma ponte entre construtos cognitivos como atenção/consciência/ monitoramento e desenvolvimento fonético-fonológico de L2, tanto em relação à percepção como no que concerne à produção (MORA; MORA-PLAZA, 2019).

Podemos reconhecer que, em termos de produção oral mais geral, considerandose os construtos de fluência, acurácia e complexidade no desenvolvimento de L2, vários trabalhos, ainda no âmbito nacional, têm colaborado significativamente ao relacionar produção oral e memória de trabalho, por exemplo (WEISSHEIMER; MOTA, 2009, 2011). No entanto, fica evidente que pouco temos avançado em relação ao papel da atenção/monitoramento na produção fonético-fonológica de L2, dado que o que encontramos na literatura são algumas considerações teóricas estabelecendo conexões e relações (muitas vezes, lineares) entre os processos cognitivos de controle e a produção oral em L2, como veremos mais adiante. Isso nos leva a evidenciar uma lacuna nas pesquisas de desenvolvimento fonético-fonológico bi/multilíngue ${ }^{3}$ (em uma perspectiva Psicolinguística), principalmente no momento atual, dada a recente ascensão das pesquisas sobre o papel de diferenças individuais (tais como atenção, memória de trabalho, aptidão, personalidade, motivação, entre outras) no desenvolvimento de L $2^{4}$.

Mantêm-se pendentes, também, questões relacionadas à demanda cognitiva gerada pelas tarefas de produção (WANG; SKEHAN; CHEN, 2019) . Conforme Köpke (2007), tarefas linguísticas em L2 distintas não produzem os mesmos resultados, justamente porque possuem demandas cognitivas diferentes. Sendo assim, é preciso conhecer qual o impacto de tais demandas cognitivas nos dados bi/multilíngues, já que questões de cunho psico-cognitivas nos próprios modelos de percepção e/ou produção linguística ainda são pouco discutidas. Tal fato abre um leque de possibilidades de pesquisa ainda pouco exploradas na Psicolinguística. De fato, mesmo no recente trabalho de Flege (2021), texto que sugere novas formas de elicitar a produção oral, não há uma evidente preocupação com as demandas cognitivas exigidas pelas diferentes tarefas de produção oral.

\footnotetext{
${ }^{2}$ No âmbito internacional, recomendamos as seguintes leituras sobre instrução explícita e treinamento perceptual: Thomson \& Derwing (2016), Munro e Derwing (2015), Thomson (2018), Carlet e Cebrian (2019), entre outros.

3 Neste artigo, usamos o termo 'multilíngue' como sinônimo de 'bilíngue'. Além disso, consideramos que aprendizes de uma Segunda Língua (L2), ainda que em contexto de L2 nãodominante, também podem ser considerados bilíngues.

${ }^{4}$ Como no trabalho de Issa et al. (2015), no qual os autores investigam a relação entre atenção e motivação no aprendizado de pronomes-objeto durante o desenvolvimento de Espanhol como L2. Revista X, v. 16, n. 5, p. 1203-1230, 2021. 
Dessa forma, dada a pouca exploração quanto às relações entre desenvolvimento fonético-fonológico bi/multilíngue e variáveis psico-cognitivas, neste artigo, buscamos discutir a lacuna referente ao relacionamento entre processos atencionais e desenvolvimento fonético-fonológico de L2, problematizando tanto alguns achados de pesquisa como também os apontamentos feitos pelo Speech Learning Model (doravante SLM/SLM-r - FLEGE, 1995, 2003; FLEGE; BOHN, 2021), modelo teórico de percepção e produção de sons em L2 que, por sua vez, perpassa armazenamento e recuperação de informações psico-acústicas ${ }^{5}$. Portanto, discutiremos três questões latentes sobre atenção não aprofundadas no SLM/SLM-r, sobretudo referentes: (i) à possível relação direta entre proficiência e refinamento de categorias fonético-fonológicas; (ii) à conjugação entre percepção-produção, a qual perpassa, inevitavelmente, um contínuo de processamento desde armazenamento à recuperação de informações; e (iii) ao impacto metodológico de se considerar o construto 'atenção', associado ao SLM/SLM-r, nas coletas de dados de produção bi/multilíngue ${ }^{6}$. Discutiremos, portanto, também a relevância de estudos que explorem tal relacionamento de forma empírica e teórica.

Cabe ressaltar que construir essa ponte entre os estudos de produção oral em L2 e atenção é, por vezes, dificultoso, de modo a implicar um processo de longo prazo, dado que ainda se discute o que de fato constitui a atenção enquanto processo/mecanismo cognitivo humano. Como dito anteriormente, existem poucos estudos em L2 que se debruçam sobre o papel da atenção e, como veremos mais adiante, quando o fazem não há a inclusão de uma medida atencional, apenas algumas considerações a respeito da relação entre processos monitorados (que, possivelmente, requerem maior atenção) e aqueles automatizados (esses considerados livres de demanda atencional). Porém, tal fato não surpreende, dado que nos próprios modelos de produção e/ou percepção de L2 (Speech Learning Model - SLM/SLM-r, FLEGE, 1995; FLEGE; BOHN, 2020; Perceptual Assimilation Model - L2, BEST; TYLER, 2007), utilizados como aporte teórico nas pesquisas de desenvolvimento linguístico, não se estabelece, com clareza, uma relação entre os processos/mecanismos cognitivos envolvidos na produção e/ou percepção linguística (como atenção e memória, por exemplo).

\footnotetext{
${ }^{5}$ Este artigo não tem a intenção de apresentar uma resenha do SLM e do SLM-r, mas, sim, de problematizar um dos pontos trazidos pelo modelo referente ao construto 'atenção'. Portanto, o artigo pressupõe conhecimento acerca do modelo por parte do/a leitor/a, de modo que aconselhamos a leitura prévia original dos textos de Flege $(1995,2003)$ e Flege e Bohn (2021).

${ }^{6}$ Julgamos que as considerações aqui feitas aplicam-se tanto a indivíduos com duas ou com várias /diversas línguas.
} 
Dentro dos referidos modelos, principalmente do SLM/SLM-r, quando se menciona o papel da atenção, pouco se explicita a respeito de tal construto. Dessa forma, fica implícita a questão de o quanto realmente esses modelos têm dado conta de uma visão psicolinguística de desenvolvimento bi/multilíngue. A partir da referida reflexão, esperamos estreitar os laços teóricos entre Fonética e Fonologia de L2 e estudos de Psicolinguística, sobretudo quanto às diferenças individuais que atuam no desenvolvimento linguístico bi/multilíngue, como o componente cognitivo atencional.

Este artigo se organiza da seguinte forma: em primeiro lugar, apresentamos as considerações do SLM/SLM-r quanto ao construto 'atenção'; logo, discutimos a noção de 'atenção' tanto em L2 como para a Psicolínguistíca e Psicologia Cognitiva, de forma geral; por último, retomamos o SLM/SLM-r, problematizando sobretudo as três lacunas teóricas e questões latentes já mencionadas. Acreditamos que, ao serem repensadas a partir das considerações sobre atenção, tais lacunas poderão ser superadas, contribuindo, ainda que em longo prazo, com a construção de uma ponte entre cognição e desenvolvimento fonético-fonológico bi/multilíngue.

\section{O SPEECH LEARNING MODEL (SLM/SLM-r) E AS QUESTÕES DE AUTO- MATICIDADE E ATENÇÃO BI/MULTILÍNGUE}

No Speech Learning Model, doravante SLM, Flege (1995; 2003) postula que os mecanismos de aprendizagem de fala (tanto produção como percepção de consoantes e vogais) permanecem intactos durante toda a vida, refutando, consequentemente, a noção de Período Crítico (LENNEBERG, 1967). Outros três postulados do SLM são: (i) Aspectos pontuais dos sons da fala são especificados em representações na memória de longo prazo, chamadas 'categorias fonéticas'; (ii) Categorias fonéticas estabelecidas na infância evoluem ao longo do tempo de vida para refletir as propriedades de todos os fones da L1 ou L2 identificados como uma realização de cada categoria; e (iii) Bilíngues esforçam-se para manter o contraste entre as categorias fonéticas da L1 e da L2, que existem em um espaço fonológico comum. Ao justificar seus postulados, Flege (1995) traz, como referência, os conceitos de níveis de processamento, ou níveis de percepção, e de processos pré-atencionais. Para Flege (1995, p. 241), portanto,

\footnotetext{
A incapacidade de discernir diferenças fonéticas entre línguas pode surgir em um ou mais níveis de processamento. Em algumas circunstâncias, os ouvintes podem ter acesso às propriedades sensoriais que distinguem pares de sons da L2 não-familiarizados (Miyawaki et al 1975; Werker e Tees 1984; Mann 1986), ou sons da L1 e da L2 (Flege 1984; Flege e Munro 1994). Contudo, eles podem deixar de fazê-lo durante o processamento online da fala. A
} 
percepção da fala torna-se automática durante o desenvolvimento da fala de L1 (Por exemplo, Linell 1982), o que libera recursos para outras tarefas de processamento (Por exemplo, Mayberry e Eichen 1991) 7 .

Partindo desses pressupostos psico-cognitivos, como dito anteriormente, Flege (1995) se apropria da noção de 'níveis de processamento', noção essa que pode indicar mais ou menos automaticidade e/ou controle cognitivo. No que diz respeito ao fato de a percepção da fala tornar-se automática, para o modelo, aprendizes prestam menos atenção aos detalhes fonéticos porque antecipam certas infomações (conforme a noção de ‘esquemas de antecipação’ de Neisser, 1976). Além disso,

É também possível que a informação sensorial que foi inicialmente processada seja descartada em uma etapa de processamento posterior, por falantes não-nativos, como não-distintiva, ou que os pesos das características se apresentem diferentemente para não-nativos e nativos de Inglês (por exemplo, Weinreich 1953; Flege e Hillenbrand 1986, 1987; Flege 1988) (FLEGE, 1995, p. 241).

Portanto, conforme o modelo, em determinado nível de processamento, certas características fonéticas (características sensoriais) são "ignoradas” por aprendizes de L2. Isso acontece devido ao mecanismo de 'esquemas de antecipação', esse propiciado pelo desenvolvimento em L1 do processamento mais automatizado da fala. Essa explicação psico-cognitiva, dada por Flege (1995), dá conta da hipótese do modelo de que sons muito próximos entre a L1 e a L2 receberão uma classificação de equivalência, resultando em sons cuja acurácia na L2 é mais difícil de alcançar. Explicando melhor, segundo o SLM, quando os aprendizes se deparam com um som da L2 que é muito próximo a um som da L1, eles vão classificar esses sons como equivalentes perceptualmente (o que o modelo chama de 'classificação de equivalência', como já mencionado). Portanto, ao produzir esses sons, os detalhes fonéticos específicos da L2 seriam ignorados.

Conforme já explicado, o modelo prevê que sons acusticamente semelhantes entre a L1 e a L2 serão mais difíceis de adquirir do que sons acusticamente mais distintos dos da L1, de modo que não haja, portanto, um 'esquema de antecipação' para esse input novo. Contudo, o SLM também prevê mudanças de classificações de categorias, porque "conforme os aprendizes de L2 ganham experiência na L2, eles podem gradualmente discernir a diferença fonética em certos sons da L2 e o som mais próximo da L1." (FLEGE, 1995, p. 263).

\footnotetext{
${ }^{7}$ Todas as traduções são de nossa responsabilidade. 
Posteriormente, de acordo com essas mudanças de classificações previstas pelo modelo, Flege (2003) afirma que "a filtragem do input de fala de L2 pode não persistir conforme aprendizes adquirem uma rede densa de itens lexicais que necessitam ser diferenciados foneticamente." (FLEGE, 2003, p. 9). Sendo assim, com input e proficiência suficientes, as influências da L1 quanto aos processos de percepção e produção de sons da L2 são minimizadas, e o aprendiz consegue dissimilar sons da L2 que antes haviam sido classificados como semelhantes aos sons da L1, retornando à noção de níveis de processamento. No entanto, essa percepção avançada das características finas dos sons em L2 deve requerer algum tipo de grau de atenção. Conforme os pressupostos teóricos trazidos para o modelo, o processamento da fala se torna automático durante o desenvolvimento de L1, de modo que o modelo não esclarece como e por que, em estágios mais avançados, essa automaticidade deixa de ser prioritária e o processamento passa, então, a ser mais atento aos detalhes fonético-fonológicos. Podemos considerar que, em níveis mais avançados do aprendizado, o aprendiz de L2 direciona sua atenção aos aspectos mais formais da língua do que à fluência. Se pensarmos em um contexto de sala de aula ${ }^{8}$, por exemplo, os aprendizes de uma L2 não são levados a considerar as características fonético-fonológicas desde o início do aprendizado; pelo contrário, o foco, muitas vezes, recai na ambientação cultural e no vocabulário.

Para Flege (2003), portanto, em estágios mais avançados de aprendizado de L2, o nível de processamento do input também é mais profundo, levando, por conseguinte, ao estabelecimento de novas categorias fonéticas para os sons da L2. Isso sugere que o foco de atenção nos detalhes fonéticos finos é maior em estágios mais avançados de aprendizado linguístico, ou seja, entre sujeitos que já alcançaram níveis mais altos de proficiência. Dessa forma, o que Flege $(1995,2003)$ apresenta sobre atenção e automaticidade diz respeito às concepções já mencionadas de níveis de processamento e processos pré-atencionais. Esses, então, são responsáveis pela "filtragem" do input de forma a antecipar certos padrões, ou ainda, posteriormente, refinar os padrões num estágio mais tardio do aprendizado. Além disso, percebemos uma relação, de certa forma linear, entre dissimilação de categorias fonético-fonológicas e proficiência em L2.

\footnotetext{
${ }^{8}$ Embora o SLM/SLM-r seja um modelo de percepção/produção em L2 voltado, exclusivamente, ao desenvolvimento de L2 em contexto de fala nativa (imersão), consideramos que o mesmo também pode ser aplicado ao desenvolvimento em contexto de sala de aula, pois também nesse contexto os aprendizes necessitam assimilar as categorias fonético-fonológicas da L2 em relação às categorias da L1. Além disso, consideramos que, assim como previsto no modelo, as categorias de L1 e L2 compartilham o mesmo espaço fonético-fonológico, no qual as mesmas estão (re) adaptando-se constantemente.
} 
No entanto, como discutiremos após apresentar o construto 'atenção', é possível considerar que essa relação entre proficiência e percepção (quanto maior a proficiência, maior também a percepção refinada entre categorias fonético-fonológicas da L1 e da L2), assumida por Flege $(1995,2003)$, pode não ser linear e positiva, se considerarmos que a atenção é um construto influenciado por diversas variáveis, inclusive outras variáveis individuais. Além disso, a definição de atenção, atualmente, ainda é discutida, assim como a noção dicotômica de processos controlados e automáticos que aparece no modelo. Tal dicotomia pode ser tomada como superficial, se considerarmos a complexidade dos mecanismos e processos cognitivos. Modelos de atenção mais recentes, como o Attention Network Task (ANT - FAN et al., 2002), por exemplo, partem de uma visão teórica que rompe com essa noção dicotômica entre automaticidade/controle e, por outro lado, consideram questões anatômicas e funcionais.

Na versão atualizada do modelo (Speech Learning Model Revised - FLEGE; BOHN, 2021), além de os autores focarem no aprendizado naturalístico, algumas mudanças quanto às premissas principais são propostas, sendo elas: (i) as categorias fonéticas são baseadas em distribuições estatísticas; (ii) os aprendizes de L2 de qualquer idade fazem uso dos mesmos mecanismos e processos para aprender a fala em L2 utilizados pelas crianças ao aprender sua L1; e (iii) diferenças nativas versus não-nativas são onipresentes, não porque os humanos perdem a capacidade de aprender, mas porque os mecanismos e processos que funcionaram para o aprendizado da L1 não produzem os mesmos resultados no aprendizado da L2.

Observada de forma rápida, essa última premissa pode ser encarada como uma contradição à premissa anterior. No entanto, ainda que de forma superficial, tal premissa se alinha aos estudos mais gerais sobre desenvolvimento humano (cognição e neurociência), pois podemos considerar que, de forma implícita, estejam sendo ponderadas as características individuais que são afetadas pela vida adulta, como a própria capacidade atencional durante o aprendizado de um novo idioma (DEHAENE, 2020). Em termos gerais, essa última premissa alicerça a concepção de hibridismo fonético-fonológico, visto que o contato entre L1 e L2 é inevitável.

Além das modificações mencionadas, a revisão do modelo publicada em 2021 defende, prioritariamente, estudos longitudinais para que se possa mapear o desenvolvimento fonético-fonológico bi/multilíngue de forma mais holística. No entanto, quanto à influência de construtos como atenção, menos ainda é discutido na versão atual. Apenas a relação percepção-produção é bem mais explícita. Especificamente sobre atenção, Flege e Bohn (2021) enfatizam apenas que "as diferenças no nível fonético 
podem ser detectadas quando os ouvintes concentram a atenção em tais diferenças" (op. cit., p. 12). Dessa forma, na revisão do modelo, os autores reforçam o papel de uma atenção consciente no desenvolvimento e refinamento fonético-fonológico, o que não aparecia nos textos anteriores. Como vimos mais acima, o modelo falava em refinamento das categorias fonético-fonológicas em estágios mais avançados do aprendizado, mas não esclarecia como um processamento considerado automático passaria, então, a ser mais profundo e atento. Já no texto de 2021, conforme já dito, o papel do componente atencional é mencionado, ainda que não de forma aprofundada. Sendo assim, podemos considerar que, de forma geral, o SLM tem pincelado algumas questões de processamento linguístico sem se comprometer com os mecanismos que subjazem o processamento, ainda que o modelo tente dar conta tanto da percepção quanto da produção em L2.

$\mathrm{Na}$ versão de 2021 do modelo, também há uma breve argumentação acerca do papel exercido pelo peso atribuído às pistas acústicas na relação percepção-produção. Dentre os estudos mencionados por Flege e Bohn (2021) está o trabalho de Pisoni et al. (1982), que trata, justamente, de entender as mudanças nos pesos das pistas acústicas através da alocação atencional. Conforme o SLM-r, estímulos gerados com certas mudanças acústicas levam o ouvinte/aprendiz a realocar sua atenção para as pistas acústicas manipuladas. Assim, através de treinamento perceptual, por exemplo, é possível que os aprendizes se atentem às particularidades dos sons da L2. Como vemos, o construto atencional surge para dar conta, especificamente, das hipóteses do modelo relacionadas às mudanças perceptuais nas classificações de categorias fonético-fonológicas ao longo do desenvolvimento de L2, mostrando-se, portanto, um construto de extrema importância para o entendimento da relação percepção-produção. Flege e Bohn (2021) acrescentam que os aprendizes, no geral, "não são conscientes das categorias fonéticas enquanto processam a fala porque as mudanças no nível fonético não mudam o significado" (p. 12). No entanto, conforme os autores, dada a riqueza de detalhes dessas categorias fonéticas em L2, bastam 30 milissegundos para que um aprendiz, ainda que fluente, seja identificado como falante não-nativo. Portanto, no SLM-r, o refinamento das categorias fonético-fonológicas em L2 leva a uma maior acurácia na produção, mas isso só ocorre quando os ouvintes focam a atenção em tais diferenças (op. cit, p. 12).

Dessa forma, retomando principalmente a terceira mudança do modelo, apresentada na sua versão revista e explicitada acima, é possível considerar que um dos mecanismos que atuam diferentemente entre o desenvolvimento de L1 e de L2 seja o mecanismo atencional. No entanto, mesmo na versão revisitada do modelo, questões cognitivas são apenas pinceladas. 
A seguir, discutimos a pesquisa sobre o papel exercido pela atenção no aprendizado de L2 como um caminho investigativo próspero. Ademais, discutimos como a atenção pode ser acessada, diferentemente, a depender da demanda cognitiva exigida pelo tipo de instrumento de coleta de dados orais empregados. Por último, concluímos a próxima seção problematizando a importância de investigações sobre o impacto de atenção nos estudos em desenvolvimento fonético-fonológico, tanto em relação ao design de pesquisa como aos processos de percepção e produção de sons em L2.

\section{O PAPEL DA ATENÇÃO NO DESENVOLVIMENTO DE L2}

Como mencionado na introdução deste artigo, existem algumas lacunas basilares quanto à questão do papel exercido por variáveis cognitivas no desenvolvimento bi/ multilíngue, as quais são ativadas dadas as diferentes demandas requeridas em cada tipo de tarefa de produção oral (de caráter mais ou menos monitorado). Isso gera uma preocupação investigativa, não somente quanto ao papel dessas variáveis, mas também quanto aos procedimentos de coleta de dados de produção oral bi/multilíngue. Nesse sentido, ainda que algumas pesquisas em desenvolvimento oral em L2 tenham se dedicado a explorar o papel de construtos como atenção, o que temos disponível são, muitas vezes, suposições teóricas, na maior parte, sobre automaticidade (como Declerck e Kormos, 2012 e Phillips et al., 2004).

Leow (2015) explica que, no final da década de 80 e início dos anos 90, o construto 'atenção' começou a assumir uma forma mais cognitiva. Dessa forma, tal construto passou a ser visto como um recurso cognitivo que exerce um papel na aprendizagem de L2, principalmente no seu processamento. Ainda que o trabalho de Schmidt (1990) tenha inaugurado, de certa forma, a discussão sobre o papel da atenção na percepção e produção em L2, posteriormente, poucos trabalhos no nosso país, no que diz respeito à área de aquisição fonético-fonológica de L2, se debruçaram sobre essa questão, embora ela venha sendo retomada discretamente (ALVES, ZIMMER, 2005a, 2005b; GAUER, ALVES, 2020; GONÇALVES, 2020; KIVISTÖ-DE SOUZA, 2015; ZIMMER, ALVES, 2006). Dentro desse cenário, não só entender o papel exercido pelo componente atencional na aprendizagem de L2, como também explorar ou controlar tal variável no design de pesquisa, constituem tarefas importantes.

Além disso, ao iniciarmos esse apanhado teórico pelo construto 'atenção', consideramos fundamental problematizá-lo, pois as definições ainda vêm sendo discutidas pelos estudiosos. Segundo Styles (2006), já na década de 1960, alguns pesquisadores contestavam a teoria de filtro seletivo, pois algumas evidências em atenção Revista X, v. 16, n. 5, p. 1203-1230, 2021. 
visual mostravam que a seleção do estímulo poderia ocorrer depois de que a memória semântica era acessada (como no estudo de Norman, 1968), ou, ainda, que a atenção estava relacionada ao tipo de processamento e controle cognitivo (como os estudos de Allport, 1980, 1993). Dessa forma, a própria definição do que se considera 'atenção' ainda necessita de aprimoramento.

Neste artigo, partimos da recente definição de Dehaene (2020) e, a seguir, apontamos algumas questões pertinentes: "Na ciência cognitiva, 'atenção' se refere a todos os mecanismos pelos quais o cérebro seleciona informação, amplifica-a, canaliza-a e aprofunda seu processamento (...).”. Portanto, 'atenção' é, em termos gerais, um mecanismo amplo que trabalha as informações recebidas, funcionando, assim, como um grande filtro, dado que

"Nosso cérebro é constantemente bombardeado com estímulos: os sentidos da visão, audição, olfato e toque em transmissões de bits de informação por segundo. Inicialmente, todas essas mensagens são processadas em paralelo por neurônios distintos - mas seria impossível digeri-los em profundidade: os recursos do cérebro não seriam suficientes. É por isso que uma pirâmide de mecanismos de atenção, organizados como um filtro gigantesco, realiza uma triagem seletiva. Em cada estágio, nosso cérebro decide quanta importância deve atribuir a tal e tal entrada e aloca recursos apenas para as informações que considera mais essenciais." (DEHAENE, 2020, pg. 177, 178).

Portanto, em função de um ambiente extremamente rico em informações, é necessário, num primeiro momento, "filtrar" as mais relevantes e, ainda, decidir quais receberão maiores recursos atencionais, inclusive aqueles diretamente ligados a um melhor processamento do estímulo e posterior armazenamento. Dessa forma, vemos 'atenção' como um componente extremamente necessário do aprendizado de L2 (como já discutido por Leow, 2015). No caso de desenvolvimento fonético-fonológico, por exemplo, os aprendizes precisam atentar para as pistas acústicas de maior relevância para o estabelecimento das diferenças funcionais na L2, principalmente em relação aos sons mais próximos da L1 que, por sua vez, segundo os pressupostos do SLM/SLM-r, são 
os mais difíceis de distinguir ${ }^{9}$. Ainda para Dehaene (2020), a atenção é um dos quatro pilares de qualquer aprendizado (sendo eles: atenção, engajamento ativo, feedback e consolidação $)^{10}$, tornando-se, portanto, um construto de suma importância nas pesquisas de desenvolvimento de L2.

Feitas essas considerações, através da atenção, podemos considerar que os aprendizes podem alocar mais ou menos recursos no processamento e armazenamento de um estímulo (independentemente de seu caráter mais ou menos consciente). Dehaene (2020) explica que a atenção resolve o problema da saturação informacional, ou seja, da "enxurrada" de informações que recebemos constantemente por meio dos nossos sentidos. Sendo assim, através da atenção é possível processar as informações relevantes. Além disso, com a atenção consciente, há uma forte ativação neuronal, de modo a mudar forças sinápticas e, consequentemente, firmar uma "trajetória de ativação" mais profunda e de fácil acesso. Para explicitar isso, Dehaene (2020) coloca que "quando um aluno presta atenção consciente a, digamos, uma palavra em língua estrangeira que a professora acabou de apresentar, ele permite que essa palavra se propague profundamente em seus circuitos (...). Como resultado, essa palavra tem uma chance muito melhor de ser lembrada." (op. cit., p. 180).

Dessa forma, conforme Dehaene (2020), na ciência cognitiva, a atenção funciona como um grande conjunto de mecanismos que selecionam, amplificam, canalizam e aprofundam o processamento de informações. Alocam-se, portanto, recursos atencionais somente para as informações consideradas relevantes/essenciais. Dehaene (2020), inclusive, retoma o modelo de Posner $(1994)^{11}$ de três subsistemas atencionais ('alerta', 'orientação' e 'atenção executiva') e afirma que “atenção e controle executivo se desenvolvem espontaneamente com a progressiva maturação do córtex pré-frontal, que se estende pelas duas primeiras décadas de nossa vida" (op. cit., p. 196). No entanto,

\footnotetext{
${ }^{9}$ No SLM-r, a noção de 'pistas' acústicas é retomada com base em estudos da Psicologia sobre cue weighting, principalmente dos trabalhos de Holt e Lotto (2006, 2010). Conforme Flege e Bohn (2020, p. 61), o SLM-r propõe, então, a hipótese de múltiplas pistas perceptuais que definem as novas categorias da L2 e as categorias compostas L1-L2. Conforme explicitado anteriormente, para o SLM-r, estímulos manipulados com mudanças acústicas levam o ouvinte/aprendiz a realocar sua atenção para as pistas acústicas de maior relevância na L2. Assim, através de treinamento perceptual, é possível que os aprendizes atentem às particularidades dos sons da L2, refinando, portanto, as categorias de L2 e gerando maior acurácia na produção das mesmas.

${ }^{10}$ Para Dehaene (2020), 'engajamento ativo' é o segundo pilar do aprendizado e corresponde ao processo de "envolver, explorar e gerar hipóteses ativamente e testá-las no mundo externo." (op. cit., p. 209). Já 'consolidação' corresponde ao quarto pilar do aprendizado e acontece quando um processo se torna automático.

${ }^{11}$ Reformulado em Fan et al. (2002), artigo de que Posner também é autor.

Revista X, v. 16, n. 5, p. 1203-1230, 2021. 
Dehaene (2020) ressalta que esse circuito é plástico, podendo ser melhorado através do treino e da educação ${ }^{12}$.

Muitas das considerações de Dehaene (2020) parecem compilar as diversas hipóteses/modelos atencionais, dado que: (i) é preciso prestar atenção consciente para que o aprendizado ocorra (como no caso da Hipótese de Noticing, de Schmidt, 1990); (ii) prestar atenção cria um caminho, ou uma trajetória, de ativação e, posteriormente, o conhecimento será acessado mais facilmente (demandando menos esforço cognitivo, o que, para McLaughlin (1987), libera recursos atencionais e reestrutura as representações cognitivas); e (iii) existe uma rede de estruturas anatômicas específicas envolvidas na atenção (como estabelecem Tomlin e Villa, 1994).

Mais recentemente, alguns estudiosos (FAZEKAS; NANAY, 2018) têm defendido a ideia de 'atenção' como amplificação, ao contrário de seleção. Conforme Fazekas e Nanay (2018), a ideia de atenção enquanto um recurso de seleção de estímulos restringe tal recurso cognitivo ao efeito da percepção, enquanto a ideia de amplificação expande a definição de atenção à eficiência do processamento, sem desconsiderar a percepção. A atenção, portanto, seria um mecanismo maior que abarca a percepção, o processamento, bem como questões individuais no nível psicológico. Além disso, Fazekas e Nanay (2018) acrescentam que os efeitos de filtragem ocorreriam durante todo o fluxo do processamento, diferentemente das noções de graus de automaticidade e esquemas de antecipação que embasam boa parte dos postulados do SLM/SLM-r, a partir das quais se entende que a percepção de informações vai se tornando mais automática com o avanço da proficiência, desconsiderando o que, de fato, é levado da percepção para a produção. Um estudo ainda mais recente (PANICHELLO; BUSCHMAN, 2021) aponta que a atenção e a memória de trabalho podem ser considerados dois lados da mesma moeda neuronal, ou seja, compartilham os mesmos mecanismos neuroniais que atuam ao longo do processamento de um estímulo. Portanto, novamente, podemos perceber que ainda não temos uma definição clara sobre o construto 'atenção', do que resulta, também, em imprecisões nos postulados do SLM/SLM-r.

A ideia de amplificação supracitada também conversa com a definição de atenção de Dehaene (2020). Portanto, podemos sintetizar 'atenção' (até o presente momento) como um conjunto de recursos cognitivos que não somente filtram estímulos salientes, mas também elaboram, aprimoram e aprofundam informações que poderão ser acessadas

\footnotetext{
${ }^{12}$ A partir disso, podemos considerar que, ao contrário do que prevê o SLM/SLM-r sobre a relação direta entre proficiência e refinamento de categorias fonético-fonológicas, a atenção exerce um papel mais determinante em qualquer tipo de aprendizado. Retomaremos essa discussão na seção final.
} 
mais facilmente ou não, a depender dos recursos atencionais disponibilizados ao longo do processamento (desde a percepção à produção) ${ }^{13}$. Dessa forma, a alocação de recursos atencionais constitui uma variável individual que age no processo de aprendizagem de L2.

Voltando-nos à questão sobre o design de pesquisa em produção dos sons de L2, vemos que, até o momento, os estudos que se dedicaram ao papel da atenção o fizeram com base num design totalmente voltado para o tipo de tarefa, sem contar com uma medida atencional. Estudos como o de Declerck e Kormos (2012) investigaram o efeito de tarefas de dupla demanda e da proficiência na produção de fala em L2 a partir de uma tarefa que exigia a produção de fala em L2 e, concomitantemente, a digitação em um teclado especial. Os pesquisadores descobriram que as exigências da tarefa dupla tiveram um efeito negativo na acurácia da seleção lexical (para produzir a sentença exigida na tarefa de produção) e na eficiência dos processos de correção de erros. Além disso, quanto à proficiência, os resultados indicaram que o nível de proficiência influencia a velocidade e precisão da fala, como também os processos de monitoramento (tanto na condição de tarefa simples como na condição de tarefa dupla), porque os bilíngues avançados, em comparação aos intermediários, se autocorrigiram mais.

Ao comparar seus resultados com pesquisas semelhantes, realizadas com o objetivo de observar os mesmos processos em Primeira Língua (L1), Declerck e Kormos (2012) relatam que os resultados são semelhantes. Portanto, mesmo na produção de fala em L1, uma tarefa paralela diminui os processos de monitoramento. No entanto, eles afirmam que "devido à falta de automatismo na L2, o monitoramento de L1 difere do monitoramento de L2 no que respeita à quantidade de atenção disponível para detecção de erros.” (DECLERCK; KORMOS, 2012, p. 783). Dessa forma, para esses pesquisadores, a fala em L2 é muito mais monitorada, pois bilíngues corrigem muito mais, por exemplo, a aplicação correta de uma palavra dentro do discurso em L2 do que em L1. Tal afirmação é muito próxima ao que apresenta o SLM/SLM-r no que diz respeito ao desenvolvimento de processamento automático da fala durante a aquisição de L1. Portanto, novamente, a dicotomia entre automaticidade e controle é saliente.

No entanto, podemos considerar que usar uma tarefa paralela não necessariamente pode revelar o quanto de automaticidade um bilíngue apresenta em sua L2, visto que demandas de tarefa dupla diminuem o monitoramento da fala, ou seja, a atenção que se dá à fala. Logo, com esse efeito, não é possível observar o quanto de atenção o falante

${ }^{13}$ Como o SML/SLM-r tenta dar conta de percepção e produção de sons, caberia ao modelo considerar o construto atencional ao longo de todo o processamento das categorias de L2, não somente na percepção, conforme será problematizado na seção final deste artigo. 
coloca em situações reais, nas quais não necessariamente ele terá que dividir sua atenção entre a fala e outra tarefa, mas estará empenhado numa situação de comunicação real. Além disso, o que os autores fazem são suposições sobre atenção, pois, novamente, não há a coleta de uma medida atencional que permita estabelecer que há pouca atenção à fala em L2, devido uma suposta falta de automatismo.

Por outro lado, ainda seguindo um arcabouço teórico que distingue processos automáticos e controlados de forma bastante dicotômica, considerando-se que o processo de automatização advém da prática, ao pensarmos em desenvolvimento de L2, temos que quanto mais prática, mais automatizado será o uso da língua. Contudo, aspectos automatizados também são passíveis de deslizes ("erros"), o que pode ser minimizado com feedback ${ }^{14}$ (STERNBERG; STERNBERG, 2012). Entretanto, segundo os resultados encontrados por Declerck e Kormos (2012), quanto mais proficiente se é na L2, mais a fala é monitorada, corrigida, o que contradiz um pouco a definição de Sternberg e Sternberg (2012), de acordo com a qual quanto mais proficiente é um bilíngue, mais automatizado estará seu uso da L2 e menos "monitoramento" ele precisará fazer (consequentemente, menos autocorreções) $)^{15}$. Podemos considerar que tais contradições se dão devido à forma como a proficiência é mensurada, o que influencia nas pesquisas de automaticidade e atenção da fala. Passam a ser importantes, portanto, não só o resultado de um teste de proficiência, mas também dados de frequência de uso da L2, principalmente em se tratando de contexto de L2 não-dominante, como no caso das pesquisas brasileiras em desenvolvimento fonético-fonológico bi/multilíngue. Ademais, torna-se fundamental, também, a própria aplicação de um teste atencional que possa, então, fornecer uma medida desse construto.

Como já foi mencionado, Declerck e Kormos (2012) afirmam que a atenção disponível para a fala em L2 é maior do que aquela disponível para a fala em L1, o que nos leva a considerar que o desenvolvimento da automaticidade em L2 está condicionado por uma taxa muito maior de atenção do que o desenvolvimento da automaticidade na fala em L1. Dessa forma, comparando-se a automaticidade em L1 e L2 dos bilíngues, ainda haverá uma diferença entre esses dois construtos, mas isso não significa que tais

\footnotetext{
${ }^{14}$ Para Dehaene (2020), o feedback corresponde ao terceiro pilar do aprendizado, e "a qualidade e precisão do feedback que recebemos determina a rapidez com que aprendemos" (op. cit., p. 232). O feedback corresponde, portanto, à ação de informar precisamente aos aprendizes sobre seus erros, para que possam se corrigir e reformular suas informações armazenadas. Além disso, podemos entender o papel do feedback através de práticas como feedback corretivo em sala de aula (explícito e implícito), ou ainda em meio a práticas de treinamento perceptual.

${ }^{15}$ Para Sternberg e Sternberg (2012), os efeitos da prática sobre a automatização correspondem a uma curva de ascendência brusca no início do aprendizado e, logo, uma estabilização.
} 
bilíngues não tenham desenvolvido graus de automaticidade na L2, o que, conforme será problematizado na seção final deste trabalho, pode ser retomado a partir da noção de 'níveis de processamento' elencada no SLM/SLM-r.

No entanto, cabe reafirmar que essa dicotomia estanque entre processos automáticos e controlados faz parte de um modelo de processamento específico (processamento dual ${ }^{16}$. Enquanto o modelo de processamento dual tenta dar conta de diferenças no processamento das informações (processamento serial/paralelo, nível de esforço cognitivo, grau de controle, efeitos sobre a memória de longo prazo, entre outros), dada a necessidade de lidar com um ambiente extremamente complexo (SCHNEIDER; CHEIN, 2003), o modelo de Tomlin e Villa (1994) de processamento do input contesta a principal questão que embasa o primeiro modelo: a noção de capacidade limitada de processamento. Baseando-se em descobertas da neurociência, Tomlin e Villa (1994) redesenham o processamento do input com base em diferentes redes atencionais, anatomicamente distribuídas, que também desempenham outros papeis (do tipo domain general).

Portanto, propostas atencionais como o Attention Network Test (ANT - FAN et al., 2002), baseadas no modelo de Tomlin e Villa (1994), não desconsideram as diferenças de processamento (processos automáticos e controlados), mas repensam a ideia de capacidade limitada ao evidenciar, anatomicamente, áreas cerebrais distribuídas que conseguem dar conta das diversas tarefas, sem que haja uma sobrecarga cognitiva. Além disso, se descontroi a linearidade do processamento dual, no qual temos atenção somente num momento específico do processamento (na percepção do input, basicamente) e não distribuída ao longo do processamento e recuperação de informações, o que parece ser crucial na superação da lacuna encontrada no SLM/SLM-r referente à conjugação percepção-produção, como retomaremos na seção final.

Dessa forma, verificamos que ainda não háum consenso em relação aos componentes que, de fato, integram e interagem ao longo do complexo processamento de L2. Além disso, cabe mencionar que estudos que tratam de automaticidade deveriam, ainda, discutir os construtos referentes à memória declarativa e procedural (ULLMAN, 2004), dado que esse modelo de memória lida, justamente, com a forma como o conhecimento explícito (declarativo) interage com o conhecimento implícito (mais automático). Novamente, fica evidente que discutir questões relativas a cognição e processamento (e desenvolvimento) de L2 é desafiador. Os elos entre cognição, neurociência e desenvolvimento de L2, pincipalmente considerando-se o aprendizado fonético-fonológico, vêm sendo forjados

\footnotetext{
${ }^{16}$ Schneider e Shiffrin (1977).

Revista X, v. 16, n. 5, p. 1203-1230, 2021.
} 
lentamente ao longo dos anos, mas as dificuldades, muitas vezes, se dão em função da existência desse tipo de questão pendente (como o que de fato constitui o construto 'atenção', por exemplo), ou ainda, pela forma superficial como construtos cognitivos (como atenção) vêm sendo pincelados nos estudos empíricos e nos próprios modelos de percepção e produção de sons (no caso deste trabalho, o SLM/SLM-r).

A seguir, discutimos a relação entre processos atencionais e desenvolvimento fonético-fonológico de L2, retomando as três lacunas do modelo SLM/SLM-r a partir das referidas considerações sobre atenção, fazendo, também, algumas proposições quanto ao design de pesquisa na área de fonética e fonologia de L2.

\section{CONSIDERAÇÕES FINAIS: RETOMANDO O SLM/SLM-r - QUESTÕES TEÓRIAS E METODOLÓGICAS EM RELAÇÃO À ATENÇÃO}

Todos os apontamentos resenhados anteriormente neste artigo nos ajudam a (re) pensar algumas das questões latentes sobre atenção não aprofundadas no SLM/SLM-r, principalmente quanto: (i) à possível relação direta entre proficiência e refinamento de categorias fonético-fonológicas; (ii) à conjugação entre percepção-produção, a qual perpassa, inevitavelmente, um contínuo de processamento entre armazenamento e recuperação de informações psico-acústicas; e (iii) ao impacto metodológico de se considerar o construto 'atenção', associado ao SLM/SLM-r, nas coletas de dados de produção bi/multilíngue. À guiza de conclusão, iremos perpassar cada um desses pontos.

Com relação à primeira questão, como vimos, uma das premissas do SLM/SLM-r diz respeito à assimilação entre as categorias fonético-fonológicas da L1 e da L2, que, quando similares, são classificadas como perceptualmente equivalentes. Para dar suporte a essa hipótese, Flege $(1995,2003)$ traz a noção de 'esquemas de antecipação' da ciência cognitiva. Com isso, de certa forma, o modelo simplifica como um estímulo é percebido e, inclusive, produzido, pois os 'esquemas de antecipação' se constituem como processos pré-atencionais, levando a certa automaticidade no processamento somente durante a etapa de percepção. No entanto, como foi apresentado, nem todo modelo atencional considera essa dicotomia (automaticidade/controle) como basilar.

Além disso, ao prever que as classificações entre as categorias da L1 e L2 podem mudar com o avanço da proficiência, o SLM/SLM-r parece contradizer o argumento de que o processamento da fala se torna automático durante o desenvolvimento de L1. Entretanto, o cerne nesse ponto do modelo é afirmar que, no início do aprendizado de L2, todas as classificações passam por um "filtro de L1", porque as categorias são assimiladas com relação às categorias da L1 já existentes, de forma mais automática. Argumenta-se, 
no modelo, que o refinamento de categorias fonético-fonológicas acontece mais tarde no aprendizado de L2, dado o papel exercido pelo avanço na proficiência. Podemos relacionar isso com a concepção de atenção de Dehaene (2020), tendo-se 'atenção', portanto, como um mecanismo que opera de forma a lidar com a saturação de informações do ambiente. Dessa forma, a partir do momento em que aprendizes de L2 estão mais "acostumados" com os sons, com o vocabulário e com a prosódia da nova língua, podem, então, prestar mais atenção aos detalhes formais finos.

Portanto, muito embora devamos discutir o que constitui a proficiência, podemos considerar que, passados os níveis iniciais, os aprendizes começam a reorganizar e dissimilar os sistemas fonético-fonológicos da L1 e da L2, de forma a poder alocar todas as categorias de ambas as línguas a partir de um mecanismo atencional. No entanto, cabe mencionar, ainda, que a atenção pode ser considerada uma capacidade individual. Portanto, nem todos os aprendizes, mesmo em níveis mais avançados, vão apresentar o mesmo nível de atenção nos detalhes finos dos sons da L2. Isso pode, inclusive, ajudar a entender os resultados variáveis no desenvolvimento de L2.

A partir de tais considerações, ao contrário do que prevê o SLM/SLM-r sobre a relação direta entre proficiência e refinamento de categorias fonético-fonológicas, o que pode exercer um papel mais determinante no desenvolvimento de L2 será, portanto, o quanto de recursos atencionais é disponibilizado durante o aprendizado, não somente na etapa de percepção e armazenamento de informações psico-acústicas, mas também na recuperação dessas informações (ou seja, quanto de atenção um falante dispõe em situações de produção de fala em L2) ${ }^{17}$. Assim, o nível de consciência/foco no estímulo (ou na situação linguística/comunicacional, de forma mais abrangente) pode permitir um melhor processamento, armazenamento e recuperação das informações, ainda mais considerando-se a noção de atenção como amplificação, explicitada na seção anterior. Dessa forma, a atenção deve ser entendida não somente como um recurso cognitivo, mas também como uma variável individual que age ao longo do aprendizado (esse considerado um processo contínuo) e, consequentemente, na produção em L2.

Já em relação à segunda lacuna que levantamos, referente à relação entre percepção e produção, concluímos que, ainda que o modelo vise a estabelecer a ponte entre esses dois construtos, as considerações são feitas em relação às premissas que, em essência,

\footnotetext{
${ }^{17}$ Sabemos, entretanto, da dificuldade metodológica de se obter tal tipo de medida atencional 'online' ao longo da aprendizagem.
} 
lidam com a percepção de sons. Dessa forma, caberia ainda ao modelo explicitar como a atenção age no processamento fonético-fonológico e quais as consequências para a recuperação dessas informações acústicas na produção bilíngue. Caberia ao modelo, portanto, considerar o papel atencional não somente na etapa de percepção do estímulo (perceber o detalhe fino que distingue pares semelhantes entre L1-L2, por exemplo), mas também durante sua produção. Aqui, cabe retomar que, segundo a literatura em atenção, quando o processamento de um estímulo é mais profundo, cria-se uma trajetória de ativação mais sólida e de fácil acesso. Portanto, é possível considerar que a ação de atenção no aprendizado de L2 (mas não somente nesse tipo de aprendizado, conforme Dehaene, 2020) permite a percepção, o armazenamento e a recuperação da informação. Sendo assim, a atenção agiria como uma "via de mão dupla" desde a percepção até a produção, e não somente enquanto um filtro perceptual, como ainda é entendido no SLM/SLM-r.

De forma semelhante ao SLM/SLM-r, para Köpke (2007), "Em bilíngues, a necessidade de um mecanismo de controle na produção online de fala é muito mais óbvia do que em monolíngues (...), uma vez que o uso das duas línguas precisa ser controlado de acordo com o modo de linguagem (GROSJEAN, 1992)." (KÖPKE, 2007, p. 19). Dessa forma, podemos considerar que a literatura em L2, no geral, tem considerado o papel de recursos cognitivos, como atenção, ainda de forma incipiente, o que nos leva a poucos dados empíricos com base em medidas cognitivas (neste caso, atencionais) e também a limitadas suposições teóricas.

Dessa forma, já passando à última questão de discussão proposta, referente à metodologia experimental de tarefas de produção dos sons da L2, consideramos que cabe pensar metodologias mais coerentes com a investigação sobre atenção. No entanto, para que isso seja possível, também é preciso que ocorram algumas mudanças teóricas no modelo SLM/SLM-r, que, até o momento, apresenta lacunas referentes ao entendimento sobre tal construto. É importante que a pesquisa tenha esse respaldo teórico, estabelecendo a ponte teórica entre desenvolvimento de fala em L2 e a teoria de atenção, o que, conforme a discussão realizada neste artigo, ainda está contemplado de forma superficial no modelo. Sendo assim, para os desafios futuros, além de testagens que aliem dados cognitivos aos dados de percepção e/ou produção, neste momento, é preciso ainda pensar modificações no modelo que venham a abarcar essas questões em relação às possíveis diferenças entre tarefas linguísticas, considerando-se a demanda cognitiva de cada tipo de tarefa aplicada nas coletas de dados. 
Na seção anterior, vimos que, nos estudos mencionados (Declerck e Kormos, 2012 e Phillips et al., 2004), o foco recai sobre automaticidade, o que trata as questões atencionais indiretamente. O design metodológico desses estudos, portanto, é voltado para o tipo de tarefa de produção linguística (incluindo tarefa de produção concomitante a uma tarefa paralela de digitação em um teclado); dessa forma, não há uma medida atencional. Além disso, se considerarmos que os bilíngues precisam monitorar as duas línguas constantemente, tampouco podemos afirmar que o monitoramento entre a L1 e a L2 difere. A escassez de dados empíricos de atenção/controle não nos permite, até o momento, generalizar afirmações sobre atenção, inclusive automaticidade. Conforme Dehaene (2020),

\footnotetext{
"Às vezes, temos a impressão de que podemos executar duas tarefas, ou mesmo seguir duas linhas distintas de pensamento - mas isso é pura ilusão. Um experimento básico ilustra esse ponto: dê a alguém duas tarefas muito simples - por exemplo, pressionar uma tecla com a mão esquerda sempre que ouvirem um som agudo e pressionar outra tecla com a mão direita se eles veem a letra Y. Quando ambos os alvos ocorrem simultaneamente ou em sucessão próxima, a pessoa executa a primeira tarefa em uma velocidade normal, mas a execução da segunda tarefa é consideravelmente mais lenta, em proporção direta ao tempo gasto na tomada da primeira decisão. Em outras palavras, a primeira tarefa atrasa a segunda (...). Se você estiver muito concentrado na primeira tarefa, pode até perder a segunda tarefa inteiramente." (op. cit., p. 191)
}

Portanto, devido a uma capacidade limitada e, inclusive, uma necessidade de economia energética, considera-se que nosso cérebro não mantém o foco de atenção nas duas tarefas concomitantemente. Uma tarefa, inevitavelmente, será prejudicada. Então, testar produção de L2 com base em tarefas de dupla demanda pode não ser o mais adequado, visto que, inclusive em L1, uma tarefa dupla pode requerer um maior esforço cognitivo. Monitoramento e automaticidade em L2, dessa forma, vão além de dividir a atenção entre duas tarefas, inclusive se considerarmos que a atenção também é uma capacidade individual mais complexa que age sobre o processamento e recuperação de informações.

Além disso, ainda para Dehaene (2020), “A automatização libera o espaço de trabalho consciente: ao 'rotinizar' uma atividade, podemos executá-la inconscientemente, sem amarrar os recursos centrais do cérebro" (op. cit., p. 192). É necessário, portanto, que os estudos de L2 considerem não só a atenção, mas prática e contato constantes com a língua. Bialystok (2009) coloca que a necessidade de controlar duas línguas ativas 
(portanto, em competição) contribui para o desenvolvimento do sistema atencional nos bilíngues. Além disso, a literatura em ANT aponta que, quanto ao sistema atencional, bilíngues se saem melhor quando existe resolução de conflito (NOVITSKIY, SHTYROV, MYACHYKOV, 2019, por exemplo) ${ }^{18}$.

Portanto, um novo leque de investigação é aberto se considerarmos a interconexão entre as áreas de Desenvolvimento $\mathrm{Bi} /$ multilíngue (principalmente em desenvolvimento fonético-fonológico), da Psicologia Cognitiva e os achados da Neurociência. Com esse novo rumo investigativo, não só entenderemos melhor o processo de desenvolvimento bilíngue, como também poderemos (re)pensar as práticas de sala de aula, dado que, como pontua Dehaene (2020), é necessário "prestar atenção à atenção" dos aprendizes (op . cit., p. 273). A partir disso, então, cabe salientar que, no caso do desenvolvimento fonéticofonológico em L2, ainda são escassas as pesquisas que, ao mapear percepção e/ou produção, olham para tal construto cognitivo. No entanto, a relação entre desenvolvimento linguístico e o sistema atencional parece cada vez mais estreita. Portanto, cabe lançar luz, ainda que de forma exploratória, a esse tipo de relação. Como vimos, até o momento, os estudos que mencionam o construto atenção o pensam a partir da noção de automaticidade, considerando um arcabouço voltado ao processamento dual, sendo esse linear, incapaz de dar conta do contínuo entre percepção e recuperação de informações, ou seja, produção. Essa mesma lacuna encontramos no SLM/SLM-r.

Finalizando este artigo, cabe mencionar que, junto ao LABICO (Laboratório de Cognição e Bilinguismo, do Programa de Pós-Graduação em Letras na Universidade Federal do Rio Grande do Sul - UFRGS), temos pautado essas questões referentes à conjugação entre Fonética/Fonologia, Cognição e Neurociência, buscando, portanto, entender psicolinguisticamente o processo de desenvolvimento fonético-fonológico de L2. Um dos trabalhos desenvolvidos, que vem sendo elaborado pelos autores deste artigo junto ao Laboratório, visa a investigar o impacto de atenção, enquanto variável individual, no fenômeno de atrito linguístico, a partir de dados de desenvolvimento vocálico de aprendizes brasileiros avançados de Espanhol como L2 (considerando-se, portanto, as variáveis altura (F1), anterioridade/posterioridade vocálicas (F2) e duração absoluta/ relativa). Para isso, além da aplicação do Teste Atencional D2 (BRICKENKAMP,

\footnotetext{
${ }^{18}$ Dentro do teste ANT (Attention Network Test - ANT, FAN et al., 2002), uma das tarefas faz com que os participantes lidem com um conflito de itens congruentes-incongruentes. Os dados mostram que é, justamente, nessa tarefa de resolução de conflitos que bilíngues se saem melhor do que monolíngues. Em Novitskiy, Shtyrov e Myachykov (2019), portanto, os bilíngues apresentam melhor desempenho (respostas corretas) e menor tempo de reação em relação a um grupo de monolíngues na tarefa de decisão entre itens congruentes-incongruentes.
} 
ZILLMER, 2010), a coleta de dados de produção contará com três tipos de tarefas linguísticas de produção oral, considerando-se, assim, um contínuo entre tarefas menos controladas/mais controladas. As tarefas linguísticas são as seguintes:

(i) Tarefa de Produção "Nuvem de palavras": a partir da visualização de um filme silencioso curto (de no máximo 10 minutos) e, posteriormente, a apresentação de 10 a 14 palavras pré-selecionadas, os participantes deverão fazer uma descrição oral de até 10 minutos sobre o vídeo assistido;

(ii) Tarefa de Leitura de texto: os participantes deverão ler um pequeno texto em voz alta. Consideramos essa tarefa com um grau intermediário de monitoramento, por parte dos participantes, dado o contexto linguístico pré-estabelecido pelo texto em relação à tarefa anterior;

(iii)Tarefa de Leitura de Frases-Veículo: serão construídas frases-veículo, como "Digo X bem.”, sendo X a palavra-alvo. Tais frases deverão ser lidas pelos participantes. Nessa tarefa, prevemos um alto grau de monitoramento dos participantes, pois é uma leitura extremamente mecanicista e descontextualizada.

O estudo mencionado, portanto, é um exemplo de como podemos verificar se há uma relação entre as demandas cognitivas de cada tarefa linguística na produção em L2, manipulando e testando diferentes tarefas linguísticas aliadas aos dados cognitivos, neste caso, atencionais ${ }^{19}$. Percebemos que, dessa forma, podemos abrir espaço para que mais pesquisas se atentem aos construtos cognitivos envolvidos no aprendizado de idiomas. Não somente sugerimos a aplicação de testes atencionais, mas o remodelamento das próprias tarefas linguísticas de percepção/produção de fala, considerando-se as demandas cognitivas implicadas em tais tarefas. Assim, poderemos contribuir com as discussões teórias e metodológicas ainda pendentes no modelo aqui discutido, o SLM/ SLM-r. Portanto, concluímos o presente trabalho ressaltando a necessidade de que os pesquisadores de desenvolvimento bi/multilíngue, numa perspectiva psicolingúistica, enfrentem o desafio de aliar dados, seja de produção e/ou percepção, com os novos achados em cognição bi/multilíngue.

\footnotetext{
${ }^{19}$ No momento, como forma de explorar atenção, ainda que incipientemente, tal construto é mapeado como uma constante.
} 


\section{REFERÊNCIAS}

ALVES, U. K. O Papel da Instrução Explícita na Aquisição Fonológica do Inglês como L2 - Evidências Fornecidas pela Teoria da Otimidade. 2004. 336f. Dissertação (Mestrado em Letras) - Universidade Católica de Pelotas, Pelotas (RS), 2004.

ALVES, U. K. Ensino de pronúncia de línguas não-nativas: contribuições dos estudos formais e aplicados. Trabalho apresentado no Seminário Interdisciplinar Língua, Literatura e Ensino. Pato Branco, PR: Universidade Tecnológica Federal do Paraná, 2020.

ALVES, U. K. Aquisição fonético-fonológica de L2: contribuições dos estudos de instrução explícita e treinamento perceptual. Cadernos de Linguística da ABRALIN, v. 2, no 1, p. 1-28, 2021.

ALVES, U. K.; KAMPFF, F. R. Efeitos de longo prazo do treinamento perceptual na percepção e produção das plosivas iniciais surdas do inglês por estudantes brasileiros: implicações para o ensino de pronúncia. Ilha do Desterro (UFSC), v. 72, p. 375-400, 2019.

ALVES, U. K.; LUCHINI, P. L. ¿Entrenamiento perceptivo o instrucción explícita? Percepción y producción de los patrones de Voice Onset Time iniciales del inglés (LE) por estudiantes brasileños. Forma y Función, v. 33, n. 2, p.133-165, 2020.

ALVES, U. K.; MAGRO, V. Raising awareness of L2 phonology: explicit instruction and the acquisition of aspirated /p/ by Brazilian Portuguese speakers. Letras de Hoje, v. 46, p. 71-80, 2011.

ALVES, U. K.; ZIMMER, M. C. Perceber, notar e aprender: uma visão conexionista da consciência do aprendiz na aquisição fonológica de L2. Revista Virtual de Estudos da Linguagem, v. 3, n. 5, s/p, 2005a.

ALVES, U. K.; ZIMMER, M. C. A instrução explícita na aprendizagem da L2: uma abordagem conexionista. Nonada (Porto Alegre), Porto Alegre-RS, v. 8, p. 221-232, 2005 b.

BEST, C. T., TYLER, M. D. Nonnative and second-language speech perception: Commonalities and complementarities. In: MUNRO, M. J.; BOHN, O. S. (eds.). Second language speech learning: The role of language experience in speech perception and production. Amsterdã: John Benjamins, 2007, p. 13-34.

BIALYSTOK, E. Bilingualism: The good, the bad, and the indifferent. Bilingualism: Language and Cognition, p. 3-11, 2009. 
BRAWERMAN-ALBINI, A. Os efeitos de um treinamento de percepção na aquisição do padrão acentual pré-proparoxítono da Língua Inglesa por estudantes brasileiros. 2012. Tese (Doutorado em Letras) - Universidade Federal do Paraná, Curitiba, 2012.

BRICKENKAMP, R.; ZILLMER, E. D2 - Test of attention (Manual). Canadá: Hogrefe \& Huber Publishers, 2010.

CARLET, A.; CEBRIAN, J. Assessing the Effect of Perceptual Training on L2 Vowel Identification, Generalization and Long-term Effects. In: NYVAD, A. M; HEJNÁ, M.; HOJEN, A.; JESPERSEN, A. B.; SORENSEN, M. H. (Eds.). A Sound Approach to Language Matters - In Honor of Ocke-Schwen Bohn. Dept. of English, School of Communication \& Culture, Aarhus University, 2019. p. 91-119.

DECLERK, M., KORMOS, J. The effect of dual task demands and proficiency on second language speech production. Bilingualism: Language and Cognition, 15, p. 782-796, 2012. doi:10.1017/S1366728911000629

DEHAENE, S. How we learn: Why brains learn better that any machine... for now. New York: Penguim Random House, 2020.

FAN, J.; McCANDLISS, B. D.; SOMMER, T.; RAZ, AM. POSNER, M. Testing the Efficiency and Independence of Attentional Networks. Journal of Cognitive Neuroscience, p. 340-347, 2002.

FAZEKAS, P.; NANAY, B. Attention is Amplification, not Selection. British Journal for the Philosophy of Science, 2018.

FLEGE, J. E. Second language speech learning: theory, findings, and problems. In: STRANGE, W. (ed.). Speech perception and linguistic experience: Issues in crosslanguage research. Timonium: York Press, 1995. p. 233-277.

FLEGE, J. E. Assessing constraints on second-language segmental production and perception. In: MEYER, A; SCHILLER, N. (eds). Phonetics and Phonology in Language Comprehension and Production: Differences and Similarities. Berlim: Mouton de Gruyter, 2003. p. 319-355.

FLEGE, J. E. New Methods for Second Language (L2) Speech Research. In: WAYLAND, RATREE (Ed). Second Language speech learning - Theoretical and Empirical Progress. Cambridge University Press, 2021. p. 119-156.

FLEGE, J. E.; BOHN, O. S. The revised Speech Learning Model(SLM-r). In: WAYLAND, RATREE (Ed). Second Language speech learning - Theoretical and Empirical Progress. Cambridge University Press, 2021. p. 3-83. 
GAUER, L. T.; ALVES, U. K. Instrução explícita na sala de aula de L2: Uma discussão sobre atenção e processamento de L2 à luz da teoria dos sistemas dinâmicos complexos (TSDC). Uniletras, v. 42, p. 1-22, 2020. doi: 10.5212/Uniletras.v.42.16399.2020

GONÇALVES, A. R. Orthographic Effects in Speech Perception: Evidence from an Auditory Lexical Decision Task with Brazilian Speakers of English. Revista da ANPOLL, v. 1, p. 153-169, 2020.

HOLT, L. L.; LOTTO, A. J. Cue weighting in auditory categorization: Implications for first and second language acquisition. The Journal of the Acoustical Society of America, 119(5), 2006, p. 3059-3071. doi:10.1121/1.2188377

HOLT, L. L.; LOTTO, A. J. Speech perception as categorization. Attention, Perception, and Psychophysics, 72(5), 2010, p. 1218-1227.

ISSA, B. I.; MORGAN-SHORT, K.; VILLEGAS, B.; RANEY, G. An eye-tracking study on the role of attention and its relationship with motivation. EUROSLA Yearbook, 2015. doi: https://doi.org/10.1075/eurosla.15.05iss

KIVISTÖ - DE SOUZA, H. Phonological Awareness and Pronunciation in a Second Language. 2015. 500f. Tese (Doutorado em Linguística Aplicada) - Universidade de Barcelona, Espanha, 2015.

KÖPKE, B. Language attrition at the cross-roads of brain, mind, and society. In: KÖPKE, B.; SCHMID, M. S.; KEIJZER, M.; DOSTERTS. (eds). Language Attrition - Theoretical perspectives (Ed.1). Amsterdam: John Benjamins Publishing Company, 2007. p. 9-38.

LIMA JR., R. M.; ALVES, U. K. A dynamic perspective on L2 pronunciation development: bridging research and communicative teaching practice. Revista do GEL, São Paulo, v. 16, n. 2, p. 27-56, 2019.

LENNEBERG, E. H. Biological foundations of language. New York: Wiley, 1967.

LEOW, R. P. Explicit learning in the L2 classroom. Nova York: Routledge, 2015.

MCLAUGHLIN, B. Theories of second language learning. London: Edward Arnold, 1987.

MILAN, P. Efeitos do treinamento perceptual na percepção e produção dos heterotônicos por aprendizes brasileiros de Espanhol. 2009. Tese (Doutorado em Letras) - Universidade Federal do Paraná, Curitiba, 2019. 
MORA, J. C.; MORA-PLAZA. I. Contributions of Cognitive Attention Control to L2 Speech Learning. In: NYVAD, A. M.; HEIJNÁ, M.; HOJEN, A.; JESPERSEN, A. B.; SORENSEN M. H. (eds.). A Sound Approach to Language Matters - In Honor of Ocke-Schwen Bohn, 2019. p. 477-499.

MUNRO, M.; DERWING, T. Intelligibility in Research and Practice: Teaching Priorities. In: REED, M.; LEVIS, J. M. (eds.). The Handbook of English Pronunciation. Malden, MA: Wiley Blackwell, 2015. p. 377-396.

NOVITSKIY, N.; SHTYROV, Y.; MYACHYKOV, A. Conflict Resolution Ability in Late Bilinguals Improves With Increased Second-Language Proficiency: ANT Evidence. Front. Psychol., p. 1-10, 2019. https://doi.org/10.3389/fpsyg.2019.02825.

PANICHELLO, M. F.; BUSCHMAN, T. J. Shared mechanisms underlie the control of working memory and attention. Nature, 592, 2021, p. 601-605.

PEROZZO, R. V. Percepção de oclusivas não vozeadas sem soltura audível em codas finais do inglês (L2) por brasileiros: o papel do contexto fonético-fonológico, da instrução explícita e do nível de proficiência. 2013. 191f. Dissertação (Mestrado em Letras) - Universidade Federal do Rio Grande do Sul, Porto Alegre (RS), 2013.

PHILLIPS, N. A.; SEGALOWITZ, N.; O`BRIEN, I.; YAMASAKI, N. Semantic priming in a first and second language: Evidence from reaction time variability and event-related brain potentials. Journal of Neurolinguistics, p. 237-262, 2004. doi: 10.1016/S09116044(03)00055-1

PISONI, D. B.; ASLIN, R. N.; PEREY, A. J.; HENNESSY, B. L. Some effects of laboratory training on identifcation and discrimination of voicing contrasts in stop consonants. Journal of Experimental Psychology: Human Perception and Performance, 8, p. 297314, 1982.

POSNER, M. I. Attention: The mechanisms of consciousness. Proceedings of the National Academy of Sciences, 91(16), p. 7398-7403, 1994.

RODRIGUES, R. R.; ORTIZ-PREUSS, E. Efeitos de instrução explícita na aquisição da entoação em espanhol/L2. Working Papers em Linguística, v. 19, n. 2, p. 214-238, 2018.

SCHMIDT, R. The role of consciousness in second language learning. Applied Linguistics, p. 129-158, 1990. 
SCHNEIDER, W.; SHIFFRIN, R. M. Controlled and automatic human information processing: I. Detection, search, and attention. Psychological Review, 84(1), p. 1-66, 1977. https://doi.org/10.1037/0033-295X.84.1.1.

SCHNEIDER, W.; CHEIN, J. M. Controlled \& automatic processing: behavior, theory, and biological mechanisms. Cognitive Science, v. 27, p. 525-559, 2003.

SILVEIRA, R. The effects of pronunciation instruction on the acquisition of English word final consonants by Brazilian learners. 2004. 274f. Tese (Doutorado em Letras) - Universidade Federal de Santa Catarina, Santa Catarina (SC), 2004.

STERnBERG, R. J.; STERNBERG, K. Cognitive Psychology (6th Ed.). Califórnia: Wadsworth, 2012. ISBN-13: 978-1-111-34476-4

STYLES, E. A. The Psychology of Attention - Second Edition. New York: . Psychology Press, 2006.

TOMLIN, R. S.; VILLA, V. Attention in cognitive science and second language acquisition. Studies in Second Language Acquisition, p.183-203, 1994.

THOMSON, R. I. High Variability [Pronunciation] Training (HVPT): a proven technique about which every language teacher and learner ought to know. Journal of Second Language Pronunciation, v. 4, n. 2, p. 208-231, 2018.

THOMSON, R. I.; DERWING, T. Is phonemic training using nonsense or real words more effective? In: LEVIS, J.; LE, H.; LUCIC, I.; SIMPSON, E.; VO, S. (eds.). Proceedings of the 7th annual Pronunciation in Second Language Learning and Teaching Conference. Iowa State University, 2016, p. 88-97.

ULLMAN, M. T. Contributions of memory circuits to language: the declarative/procedural model. Cognition, 92, p. 231-270, 2004.

ZIMMER, M. C.; ALVES, U. K. A produção de aspectos fonético-fonológicos da segunda língua: instrução explícita e conexionismo. Linguagem \& Ensino, v. 9, n. 2, p. 101-143, 2006.

WANG, Z.; SKEHAN, P.; CHEN, G. The effects of hybrid online planning and L2 proficiency on video-based speaking task performance. Instructed Second Language Acquisition, v. 3.1, p. 53-80, 2019.

WEISSHEIMER, J.; MOTA, M. B. Individual Differences in Working Memory Capacity and the Development of L2 Speech Production. Issues in Applied Linguistics, v. 17, p. 34-52, 2009. 
WEISSHEIMER, J.; MOTA, M. B. Working Memory Capacity and and Lexical Density in L2 Speech Production. Organon (UFRGS), v. 51, p. 267-290, 2011.

Recebido em: 15 Jun. 2021.

Aceito em: 29 Jul. 2021. 